\title{
Computed tomographic assessment of lung aeration at different positive end-expiratory pressures in a porcine model of intra-abdominal hypertension and lung injury
}

\author{
Adrian Regli 1,2,3,4* $\mathbb{0}$, Siavash Ahmadi-Noorbakhsh ${ }^{4}$, Gabrielle Christine Musk ${ }^{5,6}$, David Joseph Reese ${ }^{7}$, \\ Peter Herrmann ${ }^{8}$, Martin Joseph Firth ${ }^{9}$ and J. Jane Pillow ${ }^{4}$
}

${ }^{*}$ Correspondence:

adrian.regli@gmail.com

${ }^{1}$ Department of Intensive Care, Fiona Stanley Hospital, Murdoch Drive, Murdoch, WA 6150, Australia

Full list of author information is available at the end of the article

\begin{abstract}
Background: Intra-abdominal hypertension (IAH) is common in critically ill patients and is associated with increased morbidity and mortality. High positive end-expiratory pressures (PEEP) can reverse lung volume and oxygenation decline caused by IAH, but its impact on alveolar overdistension is less clear. We aimed to find a PEEP range that would be high enough to reduce atelectasis, while low enough to minimize alveolar overdistention in the presence of IAH and lung injury.
\end{abstract}

Methods: Five anesthetized pigs received standardized anesthesia and mechanical ventilation. Peritoneal insufflation of air was used to generate intra-abdominal pressure of $27 \mathrm{cmH}_{2} \mathrm{O}$. Lung injury was created by intravenous oleic acid. PEEP levels of 5, 12, 17, 22 , and $27 \mathrm{CmH}_{2} \mathrm{O}$ were applied. We performed computed tomography and measured arterial oxygen levels, respiratory mechanics, and cardiac output 5 min after each new PEEP level. The proportion of overdistended, normally aerated, poorly aerated, and non-aerated atelectatic lung tissue was calculated based on Hounsfield units.

Results: PEEP decreased the proportion of poorly aerated and atelectatic lung, while increasing normally aerated lung. Overdistension increased with each incremental increase in applied PEEP. "Best PEEP" (respiratory mechanics or oxygenation) was higher than the "optimal CT inflation PEEP range" (difference between lower inflection points of atelectatic and overdistended lung) in healthy and injured lungs.

Conclusions: Our findings in a large animal model suggest that titrating a PEEP to respiratory mechanics or oxygenation in the presence of IAH is associated with increased alveolar overdistension.

Keywords: Intra-abdominal hypertension, Positive end-expiratory pressure, Computed tomography, Lung volumes, Acute lung injury, Abdominal compartment syndrome, Over-distension, Atelectasis, Mechanical ventilation (c) The Author(s), 2021. Open Access This article is licensed under a Creative Commons Attribution 4.0 International License, which permits use, sharing, adaptation, distribution and reproduction in any medium or format, as long as you give appropriate credit to the original author(s) and the source, provide a link to the Creative Commons licence, and indicate if changes were made. The images or other third party material in this article are included in the article's Creative Commons licence, unless indicated otherwise in a credit line to the material. If material is not included in the article's Creative Commons licence and your intended use is not permitted by statutory regulation or exceeds the permitted use, you will need to obtain permission directly from the copyright holder. To view a copy of this licence, visit http:// creativecommons.org/licenses/by/4.0/. 


\section{Background}

Intra-abdominal hypertension (IAH) is defined as a sustained intra-abdominal pressure (IAP) above or equal to $12 \mathrm{mmHg}$ [1] and occurs in around $30 \%$ of critically ill patients. Mortality increases in proportion to the degree of IAH [2].

IAH impairs function and causes permanent histological changes of various organ systems [3-5]. Furthermore, due to a cephalad shift of the diaphragm, IAH causes pulmonary atelectasis, impaired lung function and chest wall compliance as well as reduced oxygenation [4, 6-14].

Subsequently, patients with IAH frequently require mechanical ventilation, not only because IAH impairs lung function, but also as measures to reduce IAP can be ineffective $[15,16]$. However, the optimal mechanical ventilation, and more specifically, the optimal level of PEEP in patients with IAH remains debated [7, 13, 14, 17-19].

Previous experimental results show that high PEEP levels counteract the adverse respiratory effects of IAH, including lung volumes, respiratory mechanics and oxygenation $[8,11,13,20,21]$. Furthermore, higher PEEP levels may reduce the risk of ventilation-induced lung injury by preventing cyclic collapsing and reopening of alveoli in the dependent lung regions of patients with IAH [22, 23].

However, high PEEP levels might not only compromise the cardiovascular system but also cause alveolar over-distension in the non-dependent lung regions, which is associated with ventilator-induced lung injury [17-19, 22, 24].

Therefore, this study aimed to investigate the effect of PEEP on the degree of overdistension using computed tomography $(\mathrm{CT})[25,26]$. We set out to find an "optimal CT inflation PEEP range" that would be high enough to reduce atelectasis formation while causing minimal overdistention in a pig model of IAH and lung injury.

\section{Methods}

Additional details of the study methodology are provided in the online supplement (Additional file 1: 1. methods unabridged).

The study conformed to the regulations of the Australian Code for the care and use of animals for scientific purposes [27] and was approved by the Animal Ethics Committees, Murdoch University (R2588/13).

\section{Preparation of animals and ventilation}

Five anesthetized and paralyzed female pigs (Large White) with a median (IQR) weight of 29.3 (29.0-30.6) $\mathrm{kg}$ were included in this study.

The pigs were mechanically ventilated (Babylog VN500, Draeger, Lübeck, Germany) using the following settings: volume guaranteed pressure-controlled continuous mandatory ventilation (PC-CMV/VG), $\mathrm{F}_{\mathrm{i}} \mathrm{O}_{2} 0.6$, tidal volume $8 \mathrm{~mL} / \mathrm{kg}$. The initial PEEP setting was $5 \mathrm{cmH}_{2} \mathrm{O}$ and altered according to the experimental protocol (see below). The initial respiratory rate was adjusted to maintain an end-tidal $\mathrm{CO}_{2}$ of 35-45 mmHg. Subsequently, PEEP was the only ventilation setting altered throughout the remainder of the protocol. 


\section{Lung injury}

The experimental protocol was carried out first with healthy lungs and then with injured lungs (Additional file 1: 2. Figure: Experimental process). To create lung injury, we used oleic acid as previously described [11] until a P/F ratio of $<300 \mathrm{mmHg}$ was established. Mild as opposed to moderate or severe lung injury was chosen due to safety concerns in the setting of IAH.

\section{Respiratory mechanics}

End-inspiratory and end-expiratory airway and esophageal pressures were obtained and the static elastances of the respiratory system $\left(E_{\mathrm{rs}}\right)$, chest wall $\left(E_{W}\right)$ and lung $\left(E_{L}\right)$ and the transpulmonary pressures were derived as described previously [11]. Arterial oxygen and carbon dioxide tension were measured and $\mathrm{PaO}_{2}$ over fractional inspiratory oxygen concentration $(P / F$ ratio) was calculated [11].

\section{Hemodynamic parameters}

The animals remained supine throughout the study. Mean arterial blood pressure was measured at the femoral artery and cardiac output was measured by transpulmonary thermodilution [11].

Pigs were stabilized hemodynamically with $4 \%$ succinylated gelatin solution (500 mL over the first $30 \mathrm{~min}$ followed by $1 \mathrm{~mL} / \mathrm{kg} / \mathrm{h}$, Gelofusine ${ }^{\circledR}$, Braun, Bella Vista NSW, Australia). Noradrenalin infusion $(3 \mathrm{mg} / 50 \mathrm{~mL})$ was administered if required to maintain a mean arterial pressure $\geq 70 \mathrm{mmHg}$.

\section{Intra-abdominal pressure}

A large bore orogastric tube was inserted to allow continuous gastric drainage. IAP of $27 \mathrm{cmH}_{2} \mathrm{O}(20 \mathrm{mmHg})$ was created by the insufflation of air into the peritoneal cavity through an air-tight catheter. IAP $\geq 27 \mathrm{cmH}_{2} \mathrm{O}$ represents $\geq$ grade III IAH found in around $8 \%$ of patients $[1,2,16]$. A three-way tap connected to a transducer allowed direct measurement of IAP [6].

\section{Experimental protocol}

After performing baseline measurements, IAP of $27 \mathrm{cmH}_{2} \mathrm{O}(20 \mathrm{mmHg})$ was applied. The initial PEEP of $5 \mathrm{cmH}_{2} \mathrm{O}$ was first incrementally increased ("ascending") and then decreased ("descending"). The following increments/decrements of PEEP were applied: 5, 12, 17, 22, and $27 \mathrm{cmH}_{2} \mathrm{O}$. Recruitment maneuvers were not used. Ventilation settings were kept constant except for PEEP. All measurements were obtained 5 min after a stabilization period; physiological measurements at each PEEP level and CT measurements (see below) were only obtained at descending PEEP levels. Hysteresis was assessed by comparing measurements obtained at ascending and descending PEEP levels.

\section{Computed tomography}

A whole-lung helical CT scan (Siemens Somatom Emotion 16, Erlangen, Germany) was performed during an inspiratory and an expiratory pause (each about $20 \mathrm{~s}$ ) [28]. 
The scan parameters were standardized to $130 \mathrm{kV}, 110 \mathrm{~mA}, 1.0$ pitch, and $3 \mathrm{~mm}$ slice thickness at each tested PEEP level.

Image analyses was performed with Maluna ${ }^{\circledR}$ software (MALUNA 3.17, Peter Herrmann, University of Göttingen, Göttingen, Germany) [6]. Based on the lung tissue density, four aeration compartments were computed: overdistended $(-1000$ to -901 Hounsfield units [HU]), normally aerated ( -900 to $-501 \mathrm{HU})$, poorly aerated ( -500 to $-101 \mathrm{HU}$ ), and non-aerated (atelectatic) lung tissue (- 100 to $200 \mathrm{HU})$ [6, 29]. Lung volumes were calculated for three segments along the dorso-ventral axis.

CT lung volumes were further analyzed in Excel (v16 for Mac, Microsoft, Redmond, Washington, USA) to derive equations that best-fitted pressure (PEEP levels) - volume (CT volumes) curves for each aeration compartment separately. Three different equations, including the Venegas equation $\left(V=a+\left[b /\left(1+e^{-(P-c) / d}\right)\right]\right)$, were assessed $[25,30$, $31]$. The best fit defined the curve resulting in the smallest root mean square between the measured and calculated pressure-volume points. We calculated lower and upper inflection points as previously described [30]. We defined an "optimal CT inflation PEEP range" as the difference between the lower inflection points $(P=c-2 d)$ of both the atelectatic and overdistended lung.

\section{Statistics}

A linear mixed model was applied to assess the effect of factors (IAH, lung injury, ascending vs descending PEEP) and covariates (PEEP) on different variables using SPSS (v25, IBM, St Leonards NSW, Australia). This approach accounted for the correlation between the repeated measures on each pig. Main effect was used for analysis of respiratory and hemodynamic outcomes. Main effect plus an interaction with lung segments (PEEP and lung injury) was used for CT measured lung volumes. Laterality (left/ right) was included as a fixed factor in the linear mixed model. Differences between pigs were accounted for as a random effect. Missing values were imputed based on the average relative differences between any pig with missing data and the other animals. Wilcoxon-Signed Rank test was used to compare optimum PEEP levels between healthy and injured lungs. Linear regression was performed to assess for correlations. A $p$ value of $<0.05$ was considered statistically significant. For descriptive statistics, median (IQR) is reported.

\section{Results}

One pig died during the protocol after lung injury was induced at the highest PEEP level of $27 \mathrm{cmH}_{2} \mathrm{O}$. Therefore, we were unable to perform CT analysis or cardio-respiratory measurements with descending PEEP levels in this pig. The remaining results were used as described above. All other pigs survived to study completion.

\section{Effect of oleic acid}

To create lung injury, we required $0.4(0.4-0.8) \mathrm{mL} / \mathrm{kg}$ IV oleic acid. The resulting P/F ratio of injured lungs before abdominal inflation was 153 (146-232) $\mathrm{mmHg}$ (Table 1, Additional file 1: 3. Figure: Effect of IAH and lung injury on P/F ratio). Lung injury increased plateau airway and expiratory esophageal pressure, and increased $E_{\mathrm{rs}}$ consequent to increased $E_{L}$. 
Table 1 Effect of PEEP on expiratory cardio-respiratory variables

\begin{tabular}{|c|c|c|c|c|c|c|c|}
\hline IAP, $\mathrm{cmH}_{2} \mathrm{O}$ & $B L$ & 27 & 27 & 27 & 27 & 27 & P, PEEP \\
\hline $\begin{array}{l}\text { PEEP, } \mathrm{cmH}_{2} \mathrm{O} \\
(\% \text { of IAP) }\end{array}$ & 5 & $5(19)$ & $12(44)$ & $17(63)$ & $22(81)$ & $27(100)$ & \\
\hline \multicolumn{8}{|l|}{ Healthy lungs } \\
\hline $\begin{array}{l}\text { P/F ratio, } \\
\mathrm{mmHg}\end{array}$ & $\begin{array}{l}542 \\
(539,547)\end{array}$ & $502(499,504)$ & $\begin{array}{l}532 \\
(492,554)\end{array}$ & $512(512,549)$ & $513(502,522)$ & $515(514,546)$ & 0.37 \\
\hline$P_{\text {aw, insp }} \mathrm{cmH}_{2} \mathrm{O}$ & $17(16,17)$ & $31(31,33)^{\#}$ & $37(36,38)$ & $41(38,41)$ & $43(42,44)$ & $51(51,52)$ & $<0.01$ \\
\hline$P_{\mathrm{es}, \text { exp }} \mathrm{CmH}_{2} \mathrm{O}$ & $10(6,11)$ & $12(9,12)$ & $17(14,18)$ & $21(19,21)$ & $24(23,25)$ & $27(26,27)$ & $<0.01$ \\
\hline$P_{\text {es, insp, }} \mathrm{cmH}_{2} \mathrm{O}$ & $13(11,14)$ & $29(28,30)^{\#}$ & $34(31,34)$ & $36(33,36)$ & $38(36,38)$ & $43(41,43)$ & $<0.01$ \\
\hline$E_{\mathrm{rs}} \mathrm{cmH}_{2} \mathrm{O} / \mathrm{L}$ & $39(39,42)$ & $103(99,103)^{\#}$ & $94(93,99)$ & $85(84,86)$ & $81(75,82)$ & $92(87,100)$ & $<0.01 *$ \\
\hline$E_{\mathrm{W}}, \mathrm{CmH}_{2} \mathrm{O} / \mathrm{L}$ & $16(14,18)$ & $67(64,73)^{\#}$ & $66(59,71)$ & $53(53,62)$ & $55(53,56)$ & $60(60,61)$ & 0.71 \\
\hline$E_{L^{\prime}} \mathrm{cmH}_{2} \mathrm{O} / \mathrm{L}$ & $26(21,28)$ & $35(30,41)^{\#}$ & $35(27,35)$ & $30(25,32)$ & $27(25,27)$ & $31(27,33)$ & 0.02 \\
\hline C.O., L/min & $4.2(4.1,4.5)$ & $4.4(4.0,4.7)$ & $3.9(3.6,3.9)$ & $3.2(3.2,3.4)$ & $2.9(2.8,2.9)$ & $2.8(2.7,2.9)$ & $<0.01$ \\
\hline $\begin{array}{l}\text { Total lung } \\
\text { volume, L }\end{array}$ & $1.2(1.1,1.2)$ & $0.8(0.7,0.8)^{\#}$ & $0.9(0.9,1.0)$ & $1.0(1.0,1.0)$ & $1.1(1.1,1.2)$ & $1.3(1.2,1.3)$ & $<0.01$ \\
\hline $\begin{array}{l}\text { Lung gas } \\
\quad \text { volume, } \mathrm{mL}\end{array}$ & $\begin{array}{l}721 \\
(698,791)\end{array}$ & $378(370,418)^{\#}$ & $511(501,561)$ & $620(611,649)$ & $761(743,788)$ & $903(856,908)$ & $<0.01$ \\
\hline $\begin{array}{l}\text { Lung tissue } \\
\text { mass, } g\end{array}$ & $\begin{array}{l}393 \\
(356,412)\end{array}$ & $338(316,354)$ & $355(334,358)$ & $352(329,361)$ & $353(338,369)$ & $351(322,367)$ & 0.60 \\
\hline $\begin{array}{l}\text { Overdistended, } \\
\%\end{array}$ & $2(2,2)$ & $1(1,2)$ & $2(1,3)$ & $2(2,4)$ & $4(3,5)$ & $5(4,7)$ & $<0.01$ \\
\hline $\begin{array}{l}\text { Normally aer- } \\
\text { ated, } \%\end{array}$ & $82(79,85)$ & $56(50,65)^{\#}$ & $68(63,74)$ & $75(70,80)$ & $79(76,83)$ & $82(82,86)$ & $<0.01$ \\
\hline $\begin{array}{l}\text { Poorly aerated, } \\
\%\end{array}$ & $14(11,16)$ & $32(27,36)^{\#}$ & $23(20,38)$ & $18(15,22)$ & $14(10,16)$ & $9(8,11)$ & $<0.01$ \\
\hline Atelectatic, \% & $2(1,4)$ & $10(7,15)$ & $5(4,7)$ & $3(2,4)$ & $3(2,3)$ & $2(1,2)$ & $<0.01$ \\
\hline \multicolumn{8}{|l|}{ Injured lungs } \\
\hline $\begin{array}{l}\text { P/F ratio, } \\
\mathrm{mmHg}\end{array}$ & $\begin{array}{l}153 \\
(146,232)^{\ddagger}\end{array}$ & $175(163,201)^{\ddagger}$ & $235(187,272)$ & $244(178,326)$ & $\begin{array}{l}285 \\
(240,409)\end{array}$ & $243(165,312)$ & $0.04 *$ \\
\hline$P_{\text {aw, insp, }} \mathrm{cmH}_{2} \mathrm{O}$ & $23(23,24)^{\ddagger}$ & $38(31,40)^{\#+}$ & $40(40,41)$ & $44(42,44)$ & $47(46,47)$ & $57(54,57)$ & $<0.01 *$ \\
\hline$P_{\text {es, exp }} \mathrm{CmH}_{2} \mathrm{O}$ & $10(9,19)$ & $30(30,32)$ & $34(32,38)$ & $38(34,39)$ & $40(37,41)$ & $44(39,45)$ & $<0.01 *$ \\
\hline$P_{\text {es, insp, }} \mathrm{CmH}_{2} \mathrm{O}$ & $17(14,23)$ & $16(13,18)^{\#}$ & $20(18,22)$ & $23(23,24)$ & $26(26,28)$ & $29(29,30)$ & $<0.01$ \\
\hline$E_{\mathrm{rs},} \mathrm{CmH}_{2} \mathrm{O} / \mathrm{L}$ & $73(62,75)^{\ddagger}$ & $\begin{array}{l}115 \\
(101,148)^{\# \neq}\end{array}$ & $109(102,116)$ & $101(92,103)$ & $89(85,95)$ & $105(104,106)$ & $<0.01 *$ \\
\hline$E_{W}, \mathrm{CmH}_{2} \mathrm{O} / \mathrm{L}$ & $19(17,19)$ & $62(56,63)^{\#}$ & $61(50,73)$ & $54(46,59)$ & $53(52,53)$ & $57(50,62)$ & 0.40 \\
\hline$E_{L^{\prime}} \mathrm{cmH}_{2} \mathrm{O} / \mathrm{L}$ & $50(4,53)^{\ddagger}$ & $53(49,74)^{\ddagger}$ & $42(40,50)$ & $38(36,46)$ & $35(34,38)$ & $48(45,52)$ & $<0.01 *$ \\
\hline C.O., L/min & $4.0(3.4,4.8)$ & $4.2(4.0,4.5)$ & $3.3(3.0,3.7)$ & $3.2(2.8,3.2)$ & $3.1(3.0,3.6)$ & $3.3(2.5,3.9)$ & 0.01 \\
\hline $\begin{array}{l}\text { Total lung } \\
\text { volume, L }\end{array}$ & $1.0(1.0,1.0)$ & $1.0(0.9,1.1)$ & $1.2(1.0,1.2)$ & $1.3(1.0,1.4)$ & $1.5(1.2,1.5)$ & $1.7(1.3,1.7)$ & $<0.01$ \\
\hline $\begin{array}{l}\text { Lung gas } \\
\text { volume, } \mathrm{mL}\end{array}$ & $\begin{array}{l}522 \\
(519,596)^{\ddagger}\end{array}$ & $428(381,449)$ & $569(482,609)$ & $744(570,762)$ & $885(732,933)$ & $\begin{array}{l}1024 \\
(827,1104)\end{array}$ & $<0.01$ \\
\hline $\begin{array}{l}\text { Lung tissue } \\
\text { mass, g }\end{array}$ & $\begin{array}{l}397 \\
(372,399)\end{array}$ & $446(361,454)$ & $489(381,521)$ & $526(392,546)$ & $546(424,557)$ & $548(429,560)$ & 0.01 \\
\hline $\begin{array}{l}\text { Overdistended, } \\
\%\end{array}$ & $2(2,3)$ & $2(1,2)$ & $2(2,3)$ & $3(2,3)$ & $3(3,3)$ & $5(4,6)$ & $<0.01$ \\
\hline $\begin{array}{l}\text { Normally aer- } \\
\text { ated, } \%\end{array}$ & $61(57,66)^{\ddagger}$ & $44(35,51)$ & $55(45,59)$ & $60(53,65)$ & $63(58,70)$ & $69(65,74)$ & $<0.01$ \\
\hline $\begin{array}{l}\text { Poorly aerated, } \\
\%\end{array}$ & $24(22,26)$ & $26(22,31)$ & $25(22,29)$ & $24(21,29)$ & $24(18,27)$ & $19(15,25)$ & $<0.01$ \\
\hline Atelectatic, \% & $11(8,13)$ & $26(15,35)^{\sharp \neq}$ & $18(10,23)$ & $11(7,15)$ & $6(3,7)$ & $3(24)$ & $<0.01$ \\
\hline
\end{tabular}

Bold indicates significant $p$-values or best values to determine optimum PEEP levels

BL incidcates baseline intra-abdominal pressure (IAP), otherwise IAP of $27 \mathrm{cmH}_{2} \mathrm{O}(20 \mathrm{mmHg})$ was applied. Positive endexpiratory pressure (PEEP) was increased stepwise (ascending) then decreased (descending). Only descending values are provided. Hysteresis, difference between ascending and descending PEEP; $P / F$ ratio, arterial oxygen tension/fractional inspiratory concentration of oxygen; $P_{\text {aw }}$ plateau airway pressure; $P_{\text {es }}$ esophageal pressure; insp end-inspiratory; exp endexpiratory; E eslastanc; $r_{r}$ respiratory system; ${ }_{W}$ chest wall; $L$ lung; $C . O$. cardiac output; $P_{\mathrm{a} \text {, mean }}$ mean arterial pressure. Median 
Table 1 (continued)

(IQR) are given. Mixed linear effects model was used for statistical analysis

\# $p<0.05$ between before (BL) and after IAH

${ }^{\ddagger} p<0.5$ between healthy and injured lungs

${ }^{*} p<0.05$ indicating presence of hysteresis

\section{Effect of IAH}

Median (IQR) baseline IAP were $2(0-5) \mathrm{cmH}_{2} \mathrm{O}$ [2 (0-4) mmHg] with healthy lungs and $3(3-3) \mathrm{cmH}_{2} \mathrm{O}$ [3 (2-3) $\left.\mathrm{mmHg}\right]$ after oleic acid (lung injury). Overall IAH decreased oxygenation but this finding was not confirmed in a subgroup analyzes of healthy or sick lungs (Table 1, Additional file 1: 3. Figure: Effect of IAH and lung injury on $P / F$ ratio). Plateau airway and inspiratory esophageal pressures, $E_{W}$ and $E_{L}$ increased in the presence of IAH.

\section{Effect of lung injury and IAH on CT parameters}

Because the effect of IAH, oleic acid and PEEP on segmental lung aeration at endinspiration paralleled those at end-expiration, we only describe lung aeration measured during end-expiration. Inspiratory values are presented in Additional file 1: 4. Table: Effect of PEEP on inspiratory lung aeration. While lung injury decreased gas volumes, IAH decreased gas volumes only in healthy but not in injured lungs (Table 1). Neither lung injury nor IAH affected tissue mass. The effect of lung injury and IAH were more pronounced on a segmental level (Additional file 1: 5. Table: Effect of IAH and lung injury on segmental lung aeration, Additional file 1: 6. Figure: Effect of IAH and lung injury on segmental lung volumes). In the dorsal dependent lung segments, lung injury and IAH decreased the segmental proportion of normally aerated lung due to an increase in atelectatic lung.

Throughout the different experimental conditions, atelectatic and poorly aerated lung changes dominated in the dorsal dependent lung segments, whereas the changes in overdistension dominated in the ventral non-dependent lung segments (Fig. 1, Additional file 1: 5. Table: Effect of IAH and lung injury on segmental lung aeration, Additional file 1: 7. Table: Effect of PEEP on ventral and dorsal aeration).

The proportion of atelectatic lung correlated best with oxygenation, $E_{\mathrm{rs}}$ and $E_{L}$ (Additional file 1: 8. Table: Correlation between lung aeration and different lung parameters).

\section{Effect of PEEP}

\section{Healthy lungs}

In the presence of IAH and healthy lungs, high PEEP did not affect oxygenation but increased airway plateau and esophageal pressure, and decreased $E_{r s}$ due to decreased $E_{L}$ (Table 1, Additional file 1: 9. Figure: Effect of PEEP on $P / F$ ratio). Furthermore, blood pressure and cardiac output decreased (Additional file 1: 10. Table: Effect of PEEP on cardio-respiratory variables). In addition, gas volumes increased, but tissue mass was not affected. The overall proportion of normally aerated lungs increased due to a decrease in poorly aerated and atelectatic lung, with a parallel increase in the overall proportion of overdistended lung (Fig. 1). 

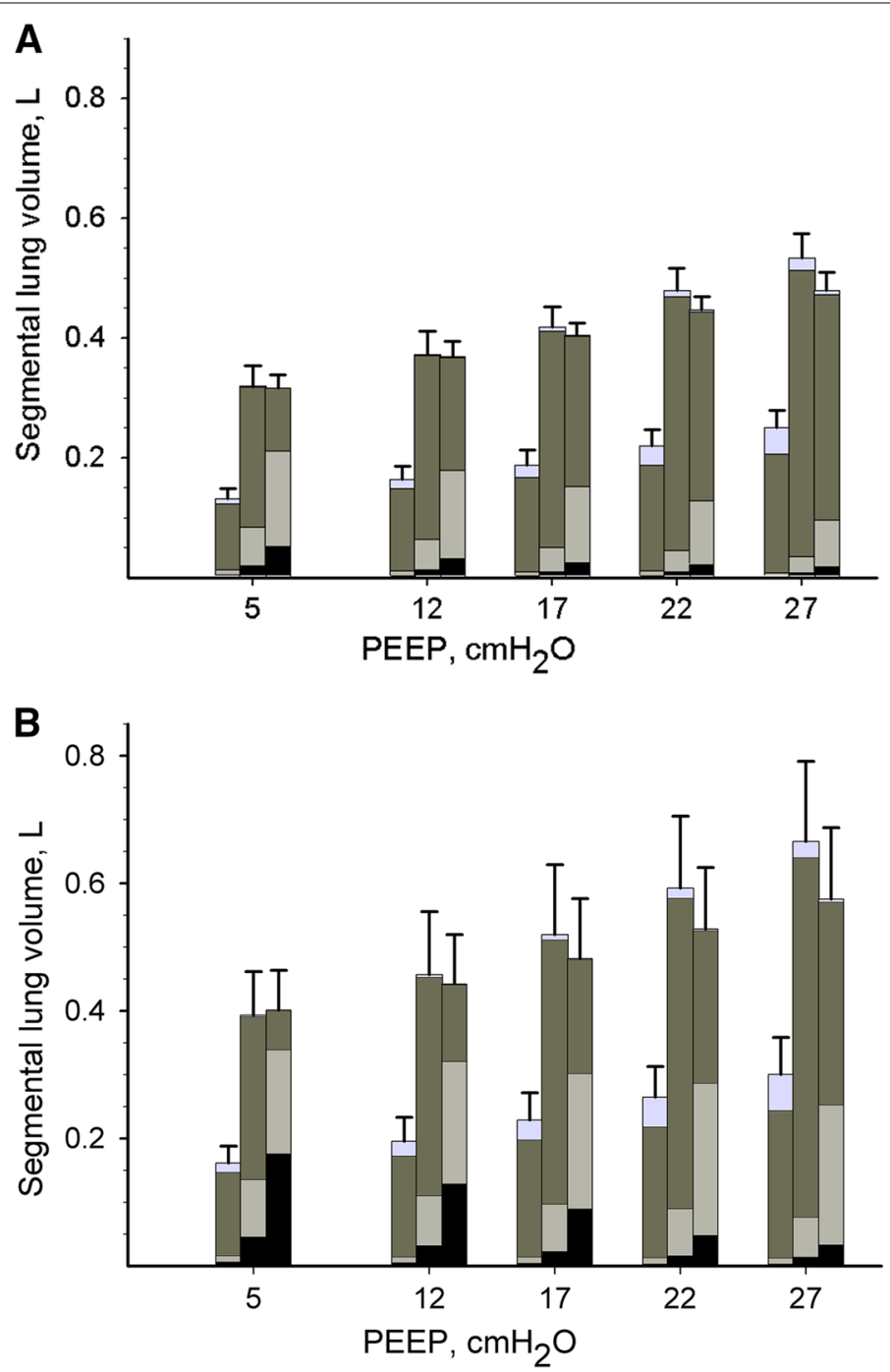

Fig. 1 Effect of descending positive end expiratory pressure (PEEP) level on end-expiratory segmental lung volumes measured by computed tomography with healthy lungs (a) and after creating lung injury (b). Abdomen was inflated to an intra-abdominal pressure of $27 \mathrm{cmH}_{2} \mathrm{O}(20 \mathrm{mmHg})$. Three lung segments are depicted at each condition with left to right representing ventral, medial and dorsal lung segment, respectively. Segmental lung volumes are a composite of overdistended (light grey, -1000 to $-901 \mathrm{HU}$ ), normally aerated (dark grey, -900 to $-501 \mathrm{HU}$ ), poorly aerated (light grey third from top, -500 to $-101 \mathrm{HU}$ ) and non-aerated atelectatic lung (black, - 100 to $200 \mathrm{HU}$ ). Mean and SE are shown. See Table 1 for statistical comparisons

The Venegas equation best described the PEEP-CT volume data sets when compared with the exponential and linear equations (smallest root mean square) (Additional file 1: 11. Table: Tested equations to fit pressure-volume data). Figure 2 shows end-expiratory pressure-volume curves for atelectatic and overdistended lung. Table 2 presents optimum PEEP levels based on different titration targets. In healthy lungs, the "optimal CT inflation PEEP range" was 7.5 to $14.9 \mathrm{cmH}_{2} \mathrm{O}$. 
Injured lungs

In the presence of IAH and injured lungs, increased PEEP improved oxygenation (Table 1, Additional file 1: Effect of PEEP on $P / F$ ratio). The effect of PEEP on plateau airway, end-expiratory, and end-inspiratory esophageal pressures, $E_{\mathrm{rs}}$ and $E_{L}$ as well as gas volumes and the overall and segmental aeration compartments (overdistended, normally aerated, poorly aerated and atelectatic lung) paralleled those found in healthy lungs (Fig. 1, Table 1). In contrast, PEEP increased tissue mass in the presence of IAH and injured lungs. The "optimal CT distension PEEP range" was 8.1 to $13.3 \mathrm{cmH}_{2} \mathrm{O}$.
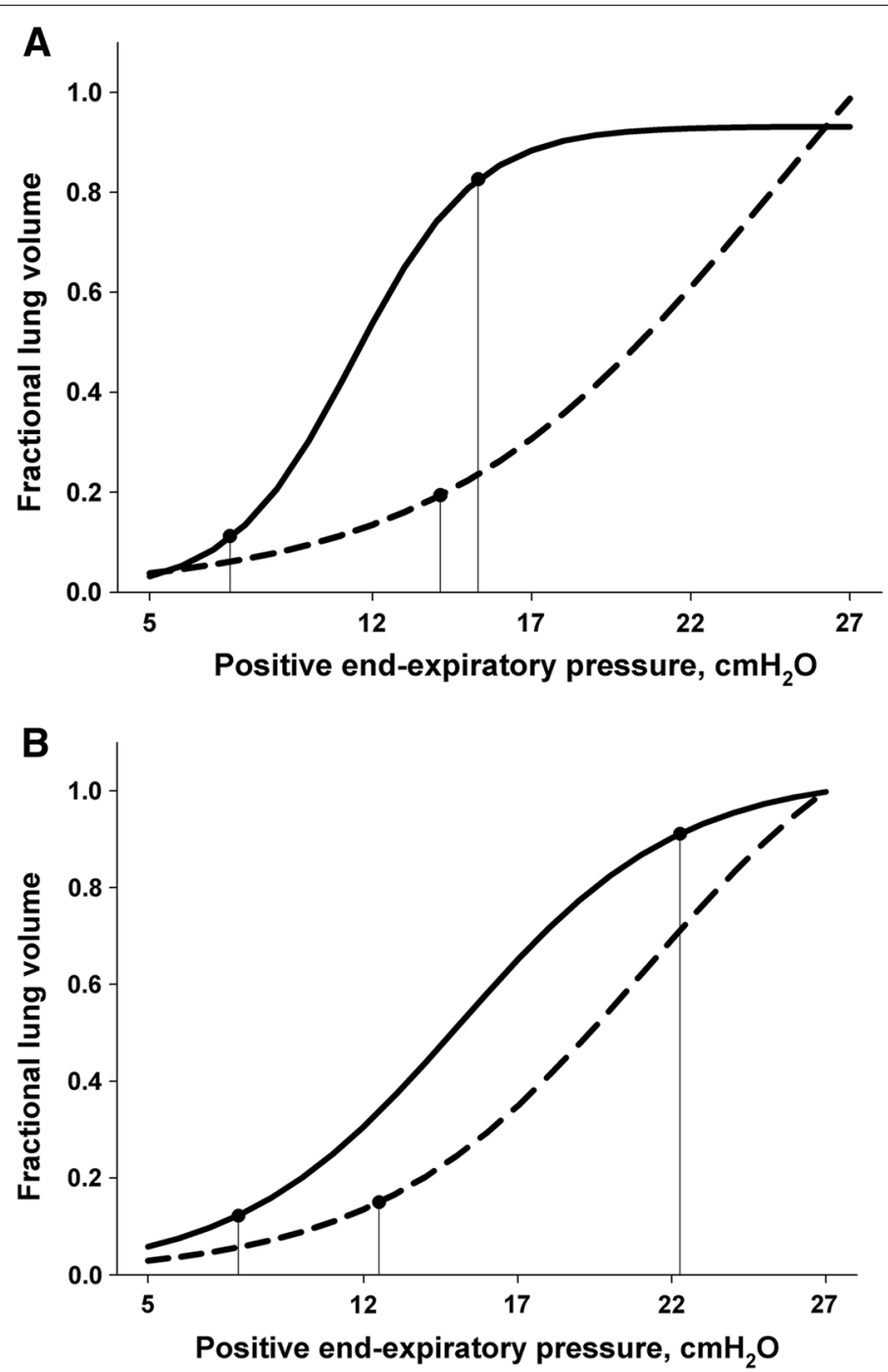

Fig. 2 End-expiratory pressure-volume curves for atelectatic (solid line) and overdistended lung volume (dashed line) are depicted for healthy (a) and injured lungs (b). Fractional lung volumes are given as the difference between 5 and $27 \mathrm{cmH}_{2} \mathrm{O}$ of positive end-expiratory pressure (PEEP). Median pressure-volume curves were derived, and lower and upper inflection points were calculated using the Venegas equation [30]. For atelectatic lung, lower and upper inflection points and for overdistended lung, lower inflection points are provided 
Table 2 Optimum PEEP relative to titration targets

\begin{tabular}{llll}
\hline PEEP titration targets & $\begin{array}{l}\text { Healthy lungs } \\
\text { PEEP, } \mathbf{~ m m H}_{\mathbf{2}} \mathbf{O}\end{array}$ & $\begin{array}{l}\text { Injured lungs } \\
\text { PEEP, } \mathbf{c m H}_{\mathbf{2}} \mathbf{O}\end{array}$ & $p$ \\
\hline P/F ratio, highest & $12(12,27)$ & $22(22,22)$ & 0.416 \\
$E_{\mathrm{rs},}$ lowest & $22(22,22)$ & $22(22,22)$ & 0.317 \\
$E_{W^{\prime}}$ lowest & $22(17,22)$ & $22(17,22)$ & 0.854 \\
$E_{L}$, lowest & $22(22,22)$ & $22(17,22)$ & 0.180 \\
C.O., highest & $5(5,5)$ & $5(5,5)$ & 0.317 \\
Lung gas volume, highest & $27(27,27)$ & $27(27,27)$ & 1.000 \\
Overdistended lung, least & $5(5,5)$ & $5(5,5)$ & 1.000 \\
Normally aerated lung, most & $27(27,27)$ & $27(27,27)$ & 1.000 \\
Atelectatic lung, least & $27(27,27)$ & $27(27,27)$ & 1.000 \\
Lower inflection point & & & \\
Lung gas volume & $8.9(8.6,9.4)$ & $9.5(9.2,10.4)$ & 0.138 \\
Overdistended lung & $\mathbf{1 4 . 9}(14.1,14.9)$ & $\mathbf{1 3 . 3}(12.5,14.6)$ & 0.345 \\
Normally aerated lung & $8.3(7.9,8.4)$ & $9.2(9.1,9.4)$ & $\mathbf{0 . 0 4 3}$ \\
Atelectatic lung & $\mathbf{7 . 5}(6.6,7.5)$ & $\mathbf{8 . 1}(7.9,8.3)$ & 0.345 \\
Upper inflection point & & & \\
Lung gas volume & $29.0(28.4,29.1)$ & $28.6(27.5,29.8)$ & 0.500 \\
Overdistended lung & $34.8(34.5,36.4)$ & $29.7(24,31.8)$ & 0.225 \\
Normally aerated lung & $27.1(26.0,28.4)$ & $29.0(28.2,29.4)$ & $\mathbf{0 . 0 4 3}$ \\
Atelectatic lung & $15.1(15.0,15.3)$ & $22.3(21.3,22.4)$ & $\mathbf{0 . 0 4 3}$
\end{tabular}

Bold indicates significant $p$-values or lower inflection points of atelectatic and overdistended lung with the difference defining an "optimal CT inflation PEEP range"

Median (IQR) are shown

PEEP positive end-expiratory pressure; $P / F$ ratio arterial oxygen tension/fractional inspiratory concentration of oxygen; $E$ elastance; ${ }_{r s}$ respiratory system; ${ }_{W}$ chest wall; $L$ lung; C.O. cardiac output

\section{Discussion}

Optimal ventilation management in patients with IAH is still debated $[7,13,14,19]$. This animal experiment uniquely explored the effect of different PEEP levels on the degree of atelectasis and overdistension using $\mathrm{CT}$ in a porcine model of IAH and lung injury. To the best of our knowledge, no other study has assessed the effect of different PEEP levels on CT measured segmental lung aeration in a porcine model of IAH and lung injury.

\section{Effect of IAH and oleic acid: affirmation of our animal model}

Overall, this study reproduced the known negative effects of IAH (via cranial diaphragmatic shift) [12] on oxygenation, lung volume and lung mechanics in healthy and injured pig lungs: IAH reduced oxygenation mainly in injured lungs and respiratory system compliance was reduced due to a decrease in chest wall compliance $[6,8,11-13,21$, $32,33]$. IAH reduced lung volumes and the proportion of normally aerated lung while increasing atelectasis formation [6,34]. These findings are consistent with the literature and provide some validity to the animal model used in this animal experiment.

To create lung injury, we used oleic acid, which is directly toxic to endothelial cells causing a varying degree of interstitial and alveolar edema, hemorrhagic infiltration and fibrin deposition [35]. Our finding that oleic acid reduced gas volume without affecting tissue mass suggests that alveolar collapse and not lung edema predominated in our animal model [36]. In contrast, other investigators describe IAH to increase lung tissue 
mass following oleic acid $[6,11,37]$ and may reflect different experimental protocols used regarding fluid management and the degree of lung injury.

\section{Overall respiratory effect of PEEP in the presence of IAH}

In line with previous work, higher PEEP levels in this project partially reversed the above changes induced by IAH: PEEP improved lung volumes and lung compliance in both healthy and injured lungs and improved oxygenation in injured lungs $[8,11,13,20,21$, 33].

Surprisingly, higher PEEP levels increased lung tissue mass in injured but not in healthy lungs, suggesting that PEEP increased lung edema in the presence of IAH and lung injury [36]. The increase in lung edema in this setting can be explained by the resulting higher intra-thoracic pressures for a given tidal volume, which may itself decrease thoracic lymph drainage [38] or increase intra-thoracic blood volume [19]. Animal studies are conflicting regarding the reported effect of PEEP on lung edema [14, $24,39]$. Thus, whether higher PEEP in patients with IAH and lung injury increases the risk of lung edema remains debatable.

We found the proportion of atelectatic lung to correlate best with oxygenation, $E_{\mathrm{rs}}$ and $E_{L}$ and suggests that oxygenation improved due to a reduction in atelectasis. In contrast to poorly aerated lung, atelectatic lung represents a shunt region that does not participate in gas exchange [25]. Muders et al. [14] found that higher PEEP levels decreased shunt perfusion and dead space ventilation in a porcine model of IAH lung injury.

\section{Effect of PEEP on segmental lung aeration in the presence of IAH}

We found higher PEEP levels increased the overall proportion of normally aerated lungs due to a decrease in poorly aerated and atelectatic lung, mainly in the dorsal dependent lung segments. However, higher PEEP levels also increased the proportion of overdistended lung in the ventral non-dependent lung segments.

We defined the "optimal CT inflation PEEP range" as the difference between the lower inflection points of the atelectatic and overdistended lung. In theory, maximal alveolar recruitment with minimal alveolar overdistension occurs within this range [25, 30]. We found the "optimal CT inflation PEEP range" in the presence of IAH to be as low as 8 to $15 \mathrm{cmH}_{2} \mathrm{O}$ and 8 to $13 \mathrm{cmH}_{2} \mathrm{O}$ in healthy and sick lungs, respectively. In contrast, we found the "best PEEP", defined as causing the smallest lung elastance [13], with 22 $\mathrm{cmH}_{2} \mathrm{O}$ (healthy and injured lungs) to be higher than the "optimal CT inflation PEEP range". Our results suggest that titrating a PEEP to respiratory mechanics or oxygenation in the presence of IAH is associated with increased alveolar overdistension, which itself increases the risk of ventilator-induced lung injury [18, 22, 24, 40].

At first sight, our "best PEEP" with $22 \mathrm{cmH}_{2} \mathrm{O}$ appears high but is comparable to works of others. Keenan et al. investigated different PEEP levels (5 to $20 \mathrm{cmH}_{2} \mathrm{O}$ ) in a porcine model of IAH and lung injury (IAP of $20 \mathrm{cmH}_{2} \mathrm{O}$ ) [13]. They concluded that the "best PEEP" was higher in the presence of IAH but was not influenced by the supine or prone position. Importantly, in the presence of IAH, their "best PEEP" of $17 \mathrm{cmH}_{2} \mathrm{O}$ equated to $85 \%$ of IAP, which was comparable to what we found $\left(22 / 27 \mathrm{cmH}_{2} \mathrm{O}, 81 \%\right)$. In addition, Muders et al. [14] found a PEEP of $22 \mathrm{cmH}_{2} \mathrm{O}$ to cause the least tidal recruitment on electric impedance tomography in the setting of IAP $20 \mathrm{cmH}_{2} \mathrm{O}$ and lung injury. 


\section{Clinical consequences}

Our findings, that titrating PEEP to the best respiratory or oxygenation was associated with increased alveolar overdistension, should be considered cautiously. Titrating PEEP based on CT measured lung aeration and applying Venegas formula to assess overdistension lower inflection point is not practical at the beside. The proportion of overdistension, depending on PEEP, was only 1 to $5 \%$ in our study. In addition, we did not measure systemic inflammation or assess histological changes to provide a sense of harm caused by increases in overdistension.

Our model included a relatively modest degree of lung injury. However, the application of higher PEEP levels in patients with mild ARDS is not recommended [41, 42]. As the studies assessing different PEEP levels in patients in ARDS do not account for the presence or absence of IAH, the optimal PEEP to be applied in patients with IAH remains unknown [42].

As IAH and PEEP only minimally affect oxygenation in healthy lungs, the role of PEEP is to provide safe protective lung ventilation and not to improve oxygenation [19].

It remains debatable, whether patients with IAH in general may benefit from higher PEEP levels to reduce the risk of atelectotrauma and ventilator-induced lung injury remains unknown $[3,19,22]$. Experimental and human data suggest that the degree of alveolar overdistension may be a more significant contributor to the release of proinflammatory cytokines than the cyclic nature of the ventilatory pattern $[24,40]$.

\section{Study limitations}

This study has several limitations. First, an animal experiment may incompletely represent lung injury and IAH found in critically ill patients. Second, we included a relatively small sample size, and one pig died mid-experiment. Third, we did not perform any histology or assess systemic inflammation changes associated with increased overdistension. Fourth, our experiment was performed in the presence of only one relatively high IAP level, we applied only a relatively modest degree of lung injury, and our experiment was not randomized. Fifth, examining more than five PEEP levels may have yielded physiologically more accurate Venegas equations. However, our findings of increased PEEP on bedside cardio-respiratory parameters are consistent with the literature in healthy $[8,19,43]$ and in injured lungs $[8,11,13,20,43,44]$, providing some confidence in the validity of our experimental model.

\section{Conclusions}

In this animal model, PEEP in the presence of IAH variably decreased the proportion of poorly aerated and atelectatic lung while increasing the proportion of normally aerated and overdistended lung in both healthy and in injured lungs. Our results suggest that titrating a PEEP to respiratory mechanics or oxygenation in the presence of IAH was associated with increased alveolar overdistension.

Abbreviations

CT: Computed tomography; $E_{\mathrm{rs}}$ : Elastance of the respiratory system; $E_{W}$ : Elastance of the chest wall; $E_{L}$ : Elastance of the lung; IAH: Intra-abdominal hypertension; IAP: Intra-abdominal pressure; PEEP: Positive end-expiratory pressures; $P / F_{\text {ratio: }}$ Arterial oxygen tension in $\mathrm{mmHg}$ over fractional inspiratory oxygen concentration. 


\section{Supplementary Information}

The online version contains supplementary material available at https://doi.org/10.1186/s40635-021-00416-5.

Additional file 1. Online Supplement.

\section{Acknowledgements}

We thank Dr. Peter Eastwood and the team from the West Australian Sleep Disorders Research Institute, Brad Gulfy from the Department of Biomedical Engineering of the Fremantle Hospital as well as the animal care team of Murdoch University for their technical assistance.

\section{Authors' contributions}

AR drafted and JP, GM, and DR reviewed research protocol. AR, SA, GM and DR performed the animal experiment. PH and DR advised on CT analysis. SA analyzed hemodynamic and AR all other data. MF advised and reviewed statistical analysis. AR drafted manuscript. All authors reviewed and contributed to the final manuscript.

\section{Funding}

This study was supported by the Spinnaker Health Research Foundation (Fremantle Hospital Research Foundation 2013) and local research funds of the Intensive Care Unit of the Fremantle Hospital.

\section{Availability of data and materials}

The data sets used and/or analyzed during the current study available from the corresponding author on reasonable request.

\section{Declarations}

\section{Ethics approval and consent to participate}

The study conformed to the regulations of the Australian Code for the care and use of animals for scientific purposes and was approved primarily by the Animal Ethics Committees of Murdoch University (R2588/13) and secondarily by the University of Western Australia (RA/3/900/77). Studies were performed at Murdoch University Veterinary Hospital.

\section{Consent for publication}

Not applicable.

\section{Competing interests}

The authors declare that they have no competing interests.

\section{Author details}

${ }^{1}$ Department of Intensive Care, Fiona Stanley Hospital, Murdoch Drive, Murdoch, WA 6150, Australia. ${ }^{2}$ Medical School, Division of Emergency Medicine, The University of Western Australia, 35 Stirling Highway, Crawley 6009, Australia. ${ }^{3}$ Medical School, The University of Notre Dame Australia, 19 Mouat Street, Fremantle 6959, Australia. ${ }^{4}$ School of Human Sciences, The University of Western Australia, 35 Stirling Highway, Crawley 6009, Australia. ${ }^{5}$ Animal Care Services, The University of Western Australia, 35 Stirling Highway, Crawley 6009, Australia. ${ }^{6}$ School of Veterinary and Life Sciences, Murdoch University, Nyarrie Drive, Murdoch 6150, Australia. ${ }^{7}$ VetCT Consultants in Telemedicine PTY LTD, 185-187 High Street, Fremantle 6160, Australia. ${ }^{8}$ Department of Anaesthesiology, Emergency and Intensive Care Medicine, University of Göttingen, Robert-Koch-Str. 40, 37075 Göttingen, Germany. ${ }^{9}$ Centre for Applied Statistics, Department of Mathematics and Statistics, The University of Western Australia, 35 Stirling Highway, Crawley 6009, Australia.

Received: 13 June 2021 Accepted: 21 September 2021

Published online: 04 October 2021

\section{References}

1. Kirkpatrick AW, Roberts DJ, De Waele J et al (2013) Intra-abdominal hypertension and the abdominal compartment syndrome: updated consensus definitions and clinical practice guidelines from the World Society of the Abdominal Compartment Syndrome. Intensive Care Med 39:1190-1206

2. Reintam Blaser A, Regli A, De Keulenaer B et al (2019) Incidence, risk factors, and outcomes of intra-abdominal hypertension in critically ill patients-a prospective Multicenter Study (IROI Study). Crit Care Med 47:535-542

3. Schachtrupp A, Toens C, Hoer J, Klosterhalfen B, Lawong AG, Schumpelick V (2002) A 24-h pneumoperitoneum leads to multiple organ impairment in a porcine model. J Surg Res 106:37-45

4. Schachtrupp A, Lawong G, Afify M, Graf J, Toens C, SchumpelickV (2005) Fluid resuscitation preserves cardiac output but cannot prevent organ damage in a porcine model during $24 \mathrm{~h}$ of intraabdominal hypertension. Shock 24:153-158

5. Malbrain ML, De Waele JJ, De Keulenaer BL (2015) What every ICU clinician needs to know about the cardiovascular effects caused by abdominal hypertension. Anaesthesiol Intensive Ther 47:388-399

6. Quintel M, Pelosi P, Caironi P et al (2004) An increase of abdominal pressure increases pulmonary edema in oleic acid-induced lung injury. Am J Respir Crit Care Med 169:534-541

7. Pelosi P, Quintel M, Malbrain ML (2007) Effect of intra-abdominal pressure on respiratory mechanics. Acta Clin Belg 62:78-88 
8. Regli A, Hockings LE, Musk GC et al (2010) Commonly applied positive end-expiratory pressures do not prevent functional residual capacity decline in the setting of intra-abdominal hypertension: a pig model. Crit Care 14:R128

9. Henzler D, Hochhausen N, Bensberg R et al (2010) Effects of preserved spontaneous breathing activity during mechanical ventilation in experimental intra-abdominal hypertension. Intensive Care Med 36:1427-1435

10. Strang CM, Freden F, Maripuu E, Hachenberg T, Hedenstierna G (2010) Ventilation-perfusion distributions and gas exchange during carbon dioxide-pneumoperitoneum in a porcine model. Br J Anaesth 105:691-697

11. Regli A, Mahendran R, Fysh ET et al (2012) Matching positive end-expiratory pressure to intra-abdominal pressure improves oxygenation in a porcine sick lung model of intra-abdominal hypertension. Crit Care 16:R208

12. Cortes-Puentes GA, Gard KE, Adams AB et al (2013) Value and limitations of transpulmonary pressure calculations during intra-abdominal hypertension. Crit Care Med 41:1870-1877

13. Keenan JC, Cortes-Puentes GA, Zhang L, Adams AB, Dries DJ, Marini JJ (2018) PEEP titration: the effect of prone position and abdominal pressure in an ARDS model. Intensive Care Med Exp 6:3

14. Muders T, Luepschen $\mathrm{H}$, Meier T et al (2020) Individualized positive end-expiratory pressure and regional gas exchange in porcine lung injury. Anesthesiology 132:808-824

15. De Waele JJ, Kimball E, Malbrain M et al (2016) Decompressive laparotomy for abdominal compartment syndrome. Br J Surg 103:709-715

16. Regli A, Reintam Blaser A, De Keulenaer B et al (2021) Intra-abdominal hypertension and hypoxic respiratory failure together predict adverse outcome: a sub-analysis of a prospective cohort. J Crit Care 64:165-172

17. Cheatham ML, Malbrain ML (2007) Cardiovascular implications of abdominal compartment syndrome. Acta Clin Belg 62:98-112

18. Pelosi P, Vargas M (2012) Mechanical ventilation and intra-abdominal hypertension: 'Beyond Good and Evil.' Crit Care 16:187

19. Regli A, Pelosi P, Malbrain MLNG (2019) Ventilation in patients with intra-abdominal hypertension: what every critical care physician needs to know. Ann Intensive Care 9:52

20. da Silva Almeida JR, Machado FS, Schettino GP, Park M, Azevedo LC (2010) Cardiopulmonary effects of matching positive end-expiratory pressure to abdominal pressure in concomitant abdominal hypertension and acute lung injury. J Trauma 69:375-383

21. Regli A, Chakera J, De Keulenaer BL et al (2012) Matching positive end-expiratory pressure to intra-abdominal pressure prevents end-expiratory lung volume decline in a pig model of intra-abdominal hypertension. Crit Care Med 40:1879-1886

22. Pinhu L, Whitehead T, Evans T, Griffiths M (2003) Ventilator-associated lung injury. Lancet 361:332-340

23. Marini JJ, Gattinoni L (2004) Ventilatory management of acute respiratory distress syndrome: a consensus of two. Crit Care Med 32:250-255

24. Pelosi P, Rocco PRM, Gama de Abreu M (2018) Close down the lungs and keep them resting to minimize ventilatorinduced lung injury. Crit Care 22:72

25. Gattinoni L, Caironi P, Pelosi P, Goodman LR (2001) What has computed tomography taught us about the acute respiratory distress syndrome? Am J Respir Crit Care Med 164:1701-1711

26. Puybasset L, Gusman P, Muller JC, Cluzel P, Coriat P, Rouby JJ (2000) Regional distribution of gas and tissue in acute respiratory distress syndrome. III. Consequences for the effects of positive end-expiratory pressure. CT Scan ARDS Study Group Adult Respiratory Distress Syndrome. Intensive Care Med 26:1215-1227

27. National Health and Medical Research Council (Australia), Australian Research Council, Universities Australia, CSIRO (Australia). Australian code for the care and use of animals for scientific purposes. National Health and Medical Research Council National Health and Medical Research Council, Universities Australia, CSIRO; 2013:8th Edition.

28. Gattinoni L, Caironi P, Cressoni M et al (2006) Lung recruitment in patients with the acute respiratory distress syndrome. N Engl J Med 354:1775-1786

29. Grasso S, Terragni P, Mascia L et al (2004) Airway pressure-time curve profile (stress index) detects tidal recruitment/ hyperinflation in experimental acute lung injury. Crit Care Med 32:1018-1027

30. Venegas JG, Harris RS, Simon BA (1998) A comprehensive equation for the pulmonary pressure-volume curve. J Appl Physiol 84:389-395

31. Regli A, De Keulenaer BL, Singh B, Hockings LE, Noffsinger B, van Heerden PV (2017) The respiratory pressureabdominal volume curve in a porcine model. Intensive Care Med Exp 5:11

32. Ranieri VM, Brienza N, Santostasi S et al (1997) Impairment of lung and chest wall mechanics in patients with acute respiratory distress syndrome: role of abdominal distension. Am J Respir Crit Care Med 156:1082-1091

33. Gattinoni L, Pelosi P, Suter PM, Pedoto A, Vercesi P, Lissoni A (1998) Acute respiratory distress syndrome caused by pulmonary and extrapulmonary disease. Different syndromes? Am J Respir Crit Care Med 158:3-11

34. Zhou JC, Xu QP, Pan KH, Mao C, Jin CW (2010) Effect of increased intra-abdominal pressure and decompressive laparotomy on aerated lung volume distribution. J Zhejiang Univ Sci B 11:378-385

35. Matute-Bello G, Frevert CW, Martin TR (2008) Animal models of acute lung injury. Am J Physiol Lung Cell Mol Physiol 295:L379-L399

36. Kuzkov VV, Suborov EV, Kirov MY et al (2010) Radiographic lung density assessed by computed tomography is associated with extravascular lung water content. Acta Anaesthesiol Scand 54:1018-1026

37. Rylander C, Högman M, Perchiazzi G, Magnusson A, Hedenstierna G (2004) Oleic acid lung injury: a morphometric analysis using computed tomography. Acta Anaesthesiol Scand 48:1123-1129

38. Lattuada M, Hedenstierna G (2006) Abdominal lymph flow in an endotoxin sepsis model: influence of spontaneous breathing and mechanical ventilation. Crit Care Med 34:2792-2798

39. Dreyfuss D, Saumon G (1998) Ventilator-induced lung injury: lessons from experimental studies. Am J Respir Crit Care Med 157:294-323

40. Bellani G, Guerra L, Musch G et al (2011) Lung regional metabolic activity and gas volume changes induced by tidal ventilation in patients with acute lung injury. Am J Respir Crit Care Med 183:1193-1199

41. Briel M, Meade M, Mercat A et al (2010) Higher vs lower positive end-expiratory pressure in patients with acute lung injury and acute respiratory distress syndrome: systematic review and meta-analysis. JAMA 303:865-873 
42. Papazian L, Aubron C, Brochard L et al (2019) Formal guidelines: management of acute respiratory distress syndrome. Ann Intensive Care 9:69

43. Regli A, De Keulenaer BL, Palermo A, van Heerden PV (2018) Positive end-expiratory pressure adjusted for intraabdominal pressure-a pilot study. J Crit Care 43:390-394

44. Krebs J, Pelosi P, Tsagogiorgas C, Alb M, Luecke T (2009) Effects of positive end-expiratory pressure on respiratory function and hemodynamics in patients with acute respiratory failure with and without intra-abdominal hypertension: a pilot study. Crit Care 13:R160

\section{Publisher's Note}

Springer Nature remains neutral with regard to jurisdictional claims in published maps and institutional affiliations.

Submit your manuscript to a SpringerOpen ${ }^{\circ}$ journal and benefit from:

Convenient online submission

- Rigorous peer review

- Open access: articles freely available online

High visibility within the field

- Retaining the copyright to your article

Submit your next manuscript at $\boldsymbol{\Delta}$ springeropen.com 